\title{
Postoperative pain after nonsurgical endodontic retreatment: Hand files versus R-Endo rotary instruments
}

\author{
(1) Nazan Yırgın Akgül,' 이 Faruk Haznedaroğlu, ${ }^{2}$ (1) Çağla Vardar² \\ 'Department of Endodontics, Adakent University Faculty of Dentistry, Turkish Republic of Northern Cyprus \\ ${ }^{2}$ Departmnet of Endodontics, Istanbul University Faculty of Dentistry, Istanbul, Turkey
}

\begin{abstract}
Objective: The purpose of this study was to determine postoperative pain after root canal therapy performed with hand files versus R-Endo rotary instruments.

Methods: Eighty single-rooted teeth were included in this study. Patients without preoperative pain were randomized by minimization program into two groups. The standardized protocol for all teeth involved local anesthesia, isolation, access and irrigation with $2.5 \% \mathrm{NaOCl}$. Root canal fillings of the teeth in group 1 were removed by Headstroem files; and, in group 2 removal was performed via R-Endo rotary instruments. Both groups were medicated with calcium hydroxide and then closed with a temporary filling material. At 4, 8, 12, 24 hours and 2, 3, 4, 5, 6, 7 days, patients recorded postreatment pain levels. Data were statistically analyzed using the chi-squared and Fischer exact tests.
\end{abstract}

Results: There was a statiscal difference in postoperative pain incidance between the groups. Postoperative pain levels were significantly higher at $4^{\text {th }}$ hour and $1^{\text {st }}, 5^{\text {th }}, 6^{\text {th }}$ and $7^{\text {th }}$ days in hand file group. There was no significant difference in the occurrence of flare-ups between the groups.

Conclusion: R-Endo rotary system was found to be effective in reducing postoperative pain in retreatment cases.

Keywords: Endodontics; postoperative pain; retreatment.

$\mathrm{P}$ ostoperative pain after root canal treatment is a common experience for patients. ${ }^{[1-3]}$ The main causes of postoperative pain are mechanical, chemical, or microbial injuries to the periapical tissues that result in acute inflammation. ${ }^{[4]}$ A mechanical reason may be over-instrumentation; whereas, chemical factors include the extrusion of medications, filling materials, or irrigants. ${ }^{[5]}$ Several factors have been identified to enlighten the occurence of postoperative pain during endodontic treatment. ${ }^{[1]}$ These include intracanal medication, ${ }^{[6]}$ apical extrusion of debris, ${ }^{[7]}$ type of treatment (initial treatment or retreatment) ${ }^{[8]}$ perira- dicular diagnosis, ${ }^{[9]}$ pulpal diagnosis ${ }^{[2]}$ presence of preoperative pain, ${ }^{[1]}$ number of sessions ${ }^{[10]}$ and host factors. ${ }^{[3]}$ Additionally, nonsurgical retreatment has been suggested as an adjunct factor for posttreatment complications. The incidence of interappointment emergencies after root canal retreatment (RCR) was found to be higher than initial root canal treatment (IRCT) ${ }^{[3]}$ Residual infection may cause exacerbation by imbalances in the host-bacteria relationship, via synergistic or additive microbial interactions, if previous root canal filling is not removed properly. Demonstration of higher flare up incidance compared to

Correspondence: Dt. Çağla Vardar. İstanbul Üniversitesi Diş Hekimliği Fakültesi,

Endodonti Anabilim Dalı, İstanbul, Turkey.

Tel: +90534 - 5296490 e-mail: caglavardar@hotmail.com

Submitted: November 24, 2020 Accepted: November 28, 2020

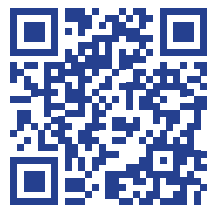


initial treatment during retreatment, ${ }^{[2,11]}$ underlines the significance of seleciting a technique that minimizes postoperaitve discomfort. ${ }^{[12]}$

One of the first rotary retreatment instruments, REndo (Micro-Mega, Besançon, France) was specially designed for the effective removal of root canal filling materials. ${ }^{[13]}$ The R-Endo instruments which contains 5 files in total are triangular in cross-section, without any radial land, have three cutting edges and a non-cutting tip. ${ }^{[14]}$ Specific designs of rotary $\mathrm{Ni}-\mathrm{Ti}$ files, canal preperation in a crown-down manner and slow rotary motion may decrease debris extrusion. ${ }^{[13]}$ It is shown that canal preperation with rotary $\mathrm{Ni}$-Ti files causes less debris material to be extruded apically. ${ }^{[15]}$ These results are consistent with other researches stating engine-driven systems caused less apical extrusion of material than hand files. ${ }^{[13-15]}$ Apically extruded material is an issue to be highlighted since it is associated with posttreatment pain and flare-ups ${ }^{[16]}$ especially in retreatment cases where the likehood of apically extruded material is high. ${ }^{[1]}$ Therefore, it might be assumed that minimizing the amount of apically extruded material should minimize postoperative reactions as well. The aim of this randomized clinical trial is to evaluate the level of postoperative pain after retreatment with hand files versus R-Endo rotary instrumentes.

\section{Materials and methods}

Following the approval of the study by University of Istanbul Review Board (protocol number 2009/1799), oral and written informed consent was obtained from all study participants. Patients were excluded from the study if one or more of the following conditions were observed: having pain and/or acute apical abscesses, ${ }^{[1]}$ current use of antibiotics and/or analgesics ${ }^{[6]}$ complicated systemic disease, ${ }^{[7]}$ having multiple teeth that required treatment to eliminate the possibility of pain referral, ${ }^{[8]}$ being pregnant, ${ }^{[9]}$ being under 18 years of age, ${ }^{[2]}$ having broken instruments. ${ }^{[10]}$

Eighty patients requiring retreatment on mature permanent maxillary and mandibular single-rooted teeth agreed to participate in the study. Patients were randomized according to the "minimization method". Two randomization factors were considered: gender and jaw where the tooth was located.

The status of the periapical tissues were evaluated according to the periapical index (PAI) by digital periapical radiographs, which were taken with parallelling technique. The included teeth had PAI scores either 1 or 2 which indicates normal and slighly altered periapical tissues respectively. ${ }^{[17]}$ Patients were asked to indicate their "pain level during the 6 hours before the appointment" on a Visual
Analog Scale (VAS). Level 10, "extremely strong pain", represented the strongest pain the participant had ever experienced. Level 0 , “absolutely nothing”, represented no pain. Each patient mark was assigned a value between 0 and 10 on the VAS. Patients recorded their preoperative pain level in the presence of the clinican to ensure that they understood the instructions. Relying on the criteria for inclusion of patients, they were expected to select the level 0 .

Each patient was anesthetized with the same solution, $40 \mathrm{mg}$ articaine hydrochloride $+0.006 \mathrm{mg} / \mathrm{mL}$ epinephrine hydrochloride (Ultracaine DS; Aventis Pharma, Istanbul, Turkey). The standart procedure for each group at the first appointment included rubber dam isolation and creation of a sterile field of operation using $30 \%$ hydrogen peroxide and $10 \%$ iodine tincture following the removal of previous coronal restorations. All teeth had $2-3 \mathrm{~mm}$ of filling material removed from the cervical part of the canal using Endoflare (Micro-Mega, Besançon, France). Then, $0.05 \mathrm{~mL}$ of Chloroform solvent was introduced into each canal to soften the gutta-percha. Two or three additional drops of solvent were applied as required to reach the working length. All rotary instruments were used at a constant speed of $300 \mathrm{rpm}$ and torque of $80 \mathrm{~N} \mathrm{~cm}^{2}$. During retreatment, the root canals were irrigated with $2.5 \%$ $\mathrm{NaOCl}$. The working lengths were determined by apex locator (Root ZX; J.Morita, Tokyo, Japan) and periapical radiographs where working length was adjusted $1 \mathrm{~mm}$ shorter of the radiological apices.

\section{Retreatment technique}

\section{Group 1 (Hand files group)}

Hand instrumentation was performed with Hedstroem (Maillefer, SA CH-1338, Ballaigues, Switzerland) files (sizes 15-30) in a circumferential filing motion. A size 30 $\mathrm{H}$-type file was introduced into the root canal by using crown-down technique until reaching the working length with a size $15 \mathrm{H}$-file.

\section{Group 2 (R-Endo group)}

R-Endo instruments were used with Inget Control $^{\circledR}$ handpiece (Micro-Mega, Besançon, France) and manipulated in a gentle in-and-out motion according to the manufacturer's instructions. The Re instrument (size 25, 0.12 Taper) and $\mathrm{Rl}$ instrument (size 25, 0.08 Taper) were used in the coronal third portion of the canal. The R2 instrument (size 25, 0.06 Taper) was used to middle third of the canal. The R3 (size 25, 0.04 Taper) and Rs instruments (size 30, 0.04 Taper) were used to the full length of the canal. 
Table 1. Gender, tooth type and PAI score by retreatment type

\begin{tabular}{|c|c|c|c|c|c|}
\hline \multirow[t]{2}{*}{ Type of retreatment } & \multirow[t]{2}{*}{ Sex M/F } & \multirow{2}{*}{$\frac{\text { Tooth }}{\text { Incisor }}$} & \multirow{2}{*}{$\frac{\text { Type }}{\text { Premolar }}$} & \multicolumn{2}{|c|}{ PAl score } \\
\hline & & & & $1-2$ & $3-5$ \\
\hline Hand files & $28 / 12$ & 27 & 13 & 27 & 13 \\
\hline R-Endo & $28 / 12$ & 27 & 13 & 28 & 12 \\
\hline
\end{tabular}

Retreatment was considered to be complete when gutta-percha removal stopped and no gutta-percha could be observed in the access opening. After then all teeth reshapped using Hero Shaper (Micro-Mega, Besançon, France) with an Inget $\mathrm{Control}^{\circledR}$ handpiece. Size 30, 0.06 Taper instrument was used in the coronal and middle thirds of the canal. Size 30, 35, 40, 0.04 taper instruments were used respectively to the full length of the canal.

At the end of instrumentation, the root canals were dried with paper points. Then, they were medicated with calcium hydroxide (MM paste, Micro-Mega,Besançon, France) paste for 7 days. Following the application of calcium hydroxide, the canal orifices were closed with a sterile dry cotton pellet and temporary restorative material with a minimum thickness of $3 \mathrm{~mm}$ (Cavit G; Espe Dental, Seefeld, Germany).

Before the final appointment, all patients were advised not to take any analgesics. They were instructed to record their posttreatment pain on VAS at $4,8,12,24$ hours and $2,3,4,5,6,7$ days. Within the first 72 hours of the appointment, If a patient had to refer to the clinic because of severe pain or swelling, it was considered a flare-up. After 7 days, the patients were instructed to return the questionnaire. Postoperative pain scores were statistically analyzed using the chi-square and Fischer exact tests. Statistical significance level was set at $\mathrm{p}<0.05$.

\section{Results}

Patients' demographics for hand instruments and R-Endo groups are shown in Table 1. The groups were similar with respect to gender, tooth type and periapical diagnosis. There was no significant difference between groups regarding patients' demographics $(\mathrm{p}>0.05)$. In both groups, there was no significant difference in postoperative pain with respect to gender, tooth type and periapical diagnosis.

3 patients from hand files group $(7.5 \%)$ and 1 patient from R-Endo group (2.5\%) experienced flare-ups that required emergency visit within 72 hours after the initial retreatment. There was no significant difference between groups regarding the incidence of flare-ups $(\mathrm{p}>0.05)$.

The data demonstrated that the pain levels in the hand files group was significantly higher than the R-Endo group $(\mathrm{p}<0.05)$ (Fig. 1). The maximum postoperative pain values were recorded at the $12^{\text {th }}$ hour for the hand file group; and, at the $8^{\text {th }}$ hour for the R-Endo group.

After the $4^{\text {th }}$ hour, the pain levels in the hand files group was significantly higher than the R-Endo group $(\mathrm{p}<0.05)$. When postoperative pain levels were compared between the groups after 8-12 hours, the difference was not statistically significant $(\mathrm{p}>0.05)$. After 1 day, the pain levels in the hand files group was significantly higher than the R-Endo group $(\mathrm{p}<0.05)$.

When postoperative pain levels were compared between the groups after 2, 3, 4 days, the difference was not statistically significant $(\mathrm{p}>0.05)$. When postoperative pain levels were compared between the groups after $5,6,7$

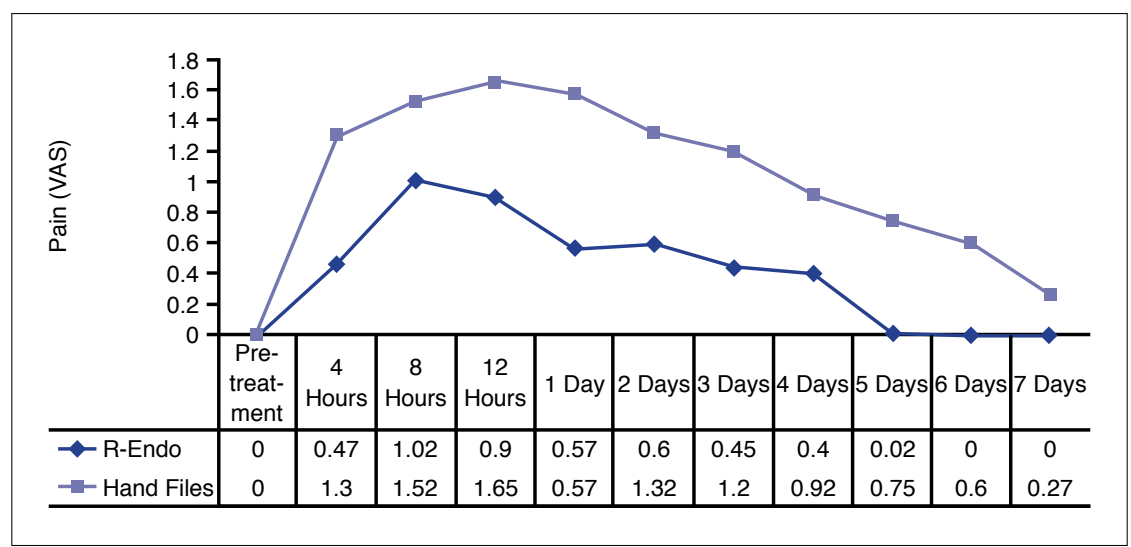

Fig. 1. Frequency of patients reporting pain during the 7 days postoperative period in the hand file and R-Endo groups. 
days, the difference was found to be statistically significant $(\mathrm{p}<0.05)$.

The postoperaitve pain completely ceased after the 5 th day for R-Endo group.

\section{Discussion}

This study aims to adress the difference in postoperative pain incidance during nonsurgical retreatment with hand files and R-Endo rotary instrumentes. The major finding of this present study indicated that hand files caused significantly more postoperative pain than R-Endo rotary instruments during nonsurgical retreatment.

It is well known that pain perception is a highly subjective and variable experience modulated by multiple physical and psychological factors. In addition, the measurement of pain is fraught with hazards and opportunities for error. $^{[18]}$ Visual Analogue Scale (VAS) is selected which is considered to be a valid and reliable ratio scale for measurement of pain.

Extreme care was taken to rule out avoidable preoperative factors that might result in postoperative pain. ${ }^{[19]}$ The study was limited to asymptomatic teeth, since preoperative pain is one of the most predictable indicators for postoperative pain. ${ }^{[3]}$ Only single-rooted teeth were included to minimize the risk of iatrogenic errors because of missed or complicated root canal anatomy. Furthermore, only patients without a contributing medical history who did not take analgesic medication recently were included so that no other pain source could interfere with pain resulting from endodontic therapy. Patients with multiple problematic teeth that required treatment were excluded to eliminate the possibility of referred pain.

Apical debris extrusion is considered as an adjuvant factor for postoperative pain, ${ }^{[20]}$ since the extruded materials such as microorganisms, dentin debris and and foreign substances may trigger an inflammatory reaction in the periradicular area. ${ }^{[16]}$ Prior investigations have revealed that removal of root canal filling material with hand files produces greater amout of apically extruded debris than rotary or reciprocating motion. ${ }^{[21-23]}$ The extent of apically extruded debris during conventional instrumentation with hand files is associated with the pump-like behaviour of the file that pushes material out of the apical foramen while manually being used in an up and down manner. ${ }^{[24]}$

In a study in which the investigators have evaluated the debris extruded apically with ProTaper, D-RaCe, R-Endo rotary instruments and hand files during retreatment, the results have shown that rotary $\mathrm{Ni}-\mathrm{Ti}$ instruments caused less apical debris extrusion compared to hand files. ${ }^{[25]} \mathrm{A}$ similar conclusion was reached by researchers who compared the apical debris extrusion during retreatment using K3, R-Endo and Hedström files; stating the rotary NiTi systems produced less debris extrusion. ${ }^{[26]}$ In an in vitro study which compared the amount of apically extruded material between resiprocationg single files and rotary file systems, researchers suggest that; although all systems lead to some amout of debris extrusion, full-sequence rotary motion may be more effective for removal of debris out of the root canal orifice thus decreasing the extrusion form the apical foramen. ${ }^{[27]}$ Eventhough these experiments ${ }^{[21-23,25-27]}$ suffer from the absence of a true representation of vital tissues, this might be the reason for the lower posttreatment pain incidance after R-Endo rotary instruments. Since this present study is an in vivo study, the amount of debris extrusion cannot be assesed; however, it might be reasonable to make a connection between the increased posttreatment pain incidance and debris extrusion. Besides the multifactorial nature of the occurance of postoperative pain, it might be concluded that the choice of instruments is one of the significant indicatives of postoperative pain.

In this clinical study, 3 patients from hand files group and 1 patient from R-Endo group experienced flare-ups within 72 hours after the initial retreatment, but the incidence of flare-ups was not significantly different. According to the in vitro studies, debris extrusion from apical foramen is independently of the preparation technique and occurs inevitibly. ${ }^{[15,28,29]}$ Torabinejad et al., ${ }^{[3]}$ reported that patients with pain or swelling before treatment were more prone to flare-ups than those with no preoperative complaints. This emphasizes the complexity of flare up mechanism. Flare up incidance was also found to be associated with multiple appointmets, retreatments, inicial pain before treatment, periapical radiolucencies and premedication with analgesics or anti-inflammatory drugs. ${ }^{[2]}$ In this study, these variables were standardized among the subjects in order minimize the probabilty of a possible flare up initiated by another factor. However, due to the complicated machanism of flare ups, some variables are beyond the control of the clinician. These factors influencing the development of flare up include local adaptation syndrome, changes in the pressure of periapical tissues, microorganisms, host factors and psychological factors. ${ }^{[5]}$

\section{Conclusion}

Although no significant difference was found regarding the incidence of flare-ups ( $>0.05)$ between the groups; at the $4^{\text {th }}$ hour, $1^{\text {st }}, 5$ th, $6^{\text {th }}$ and $7^{\text {th }}$ days, the postoperative pain levels in the hand files group was significantly higher 
than the R-Endo group $(\mathrm{p}<0.05)$. This study concluded that R-Endo instruments significantly decreased postoperative pain incidance after retreatment compared to hand files.

\section{Acknowledgements}

The authors do not declare any acknowledgements.

Conflict of interest: None declared.

Authorship contributions: Concept: N.Y.A., F.H.; Design: N.Y.A., F.H.; Supervision: F.H.; Materials: N.Y.A.; Data: N.Y.A., F.H., Ç.V.; Analysis: N.Y.A., F.H., Ç.V.; Literature search: N.Y.A., Ç.V.; Writingः N.Y.A., Ç.V.; Critical revision: F.H., C..V.

\section{References}

1. Siqueira JF Jr, Rôças IN, Favieri A, Machado AG, Gahyva SM, Oliveira JC, et al. Incidence of postoperative pain after intracanal procedures based on an antimicrobial strategy. J Endod 2002;28:457-60.

2. Imura N, Zuolo ML. Factors associated with endodontic flare-ups: a prospective study. Int Endod J 1995;28:261-5.

3. Torabinejad M, Kettering JD, McGraw JC, Cummings RR, Dwyer TG, Tobias TS. Factors associated with endodontic interappointment emergencies of teeth with necrotic pulps. J Endod 1988;14:261-6.

4. Seltzer S. Pain in endodontics. 1986. J Endod 2004;30:501-3.

5. Seltzer S, Naidorf IJ. Flare-ups in endodontics: I. Etiological factors. 1985. J Endod 2004;30:476-81

6. Trope M. Relationship of intracanal medicaments to endodontic flare-ups. Endod Dent Traumatol 1990;6:226-9.

7. Arias A, Azabal M, Hidalgo JJ, de la Macorra JC. Relationship between postendodontic pain, tooth diagnostic factors, and apical patency. J Endod 2009;35:189-92.

8. Siqueira JF Jr. Microbial causes of endodontic flare-ups. Int Endod J 2003;36:453-63.

9. Walton R, Fouad A. Endodontic interappointment flareups: a prospective study of incidence and related factors. J Endod. 1992;18:172-7.

10. DiRenzo A, Gresla T, Johnson BR, Rogers M, Tucker D, BeGole EA. Postoperative pain after 1- and 2-visit root canal therapy. Oral Surg Oral Med Oral Pathol Oral Radiol Endod 2002;93:605-10.

11. Trope M. Flare-up rate of single-visit endodontics. Int Endod J 1991;24:24-6.

12. Comparin D, Moreira EJL, Souza EM, De-Deus G, Arias A, Silva EJNL. Postoperative Pain after Endodontic Retreatment Using Rotary or Reciprocating Instruments: A Randomized Clinical Trial. J Endod 2017;43:1084-88.

13. Taşdemir T, Er K, Yildirim T, Celik D. Efficacy of three rotary $\mathrm{NiTi}$ instruments in removing gutta-percha from root canals. Int Endod J 2008;41:191-6.

14. Fenoul G, Meless GD, Pérez F. The efficacy of R-Endo rotary NiTi and stainless-steel hand instruments to remove gutta-percha and Resilon. Int Endod J 2010;43:135-41.

15. Ferraz CC, Gomes NV, Gomes BP, Zaia AA, Teixeira FB, Souza-Filho FJ. Apical extrusion of debris and irrigants using two hand and three engine-driven instrumentation techniques. Int Endod J 2001;34:354-8.

16. Seltzer S, Naidorf IJ. Flare-ups in endodontics: I. Etiological factors. J Endod 1985;11:472-8.

17. Orstavik D, Kerekes K, Eriksen HM. The periapical index: a scoring system for radiographic assessment of apical periodontitis. Endod Dent Traumatol 1986;2:20-34.

18. Law A, Logan H, Walton R. Identification of a psychosocial model as a predictor of flare-ups. J Endod 1992;18:192-3.

19. Glennon JP, Ng YL, Setchell DJ, Gulabivala K. Prevalence of and factors affecting postpreparation pain in patients undergoing two-visit root canal treatment. Int Endod J 2004;37:29-37.

20. Nekoofar MH, Sheykhrezae MS, Meraji N, Jamee A, Shirvani A, Jamee J, et al. Comparison of the effect of root canal preparation by using WaveOne and ProTaper on postoperative pain: a randomized clinical trial. J Endod 2015;41:575-8.

21. Huang X, Ling J, Wei X, Gu L. Quantitative evaluation of debris extruded apically by using ProTaper Universal Tulsa rotary system in endodontic retreatment. J Endod 2007;33:1102-5.

22. Dincer AN, Er O, Canakci BC. Evaluation of apically extruded debris during root canal retreatment with several NiTi systems. Int Endod J 2015;48:1194-8.

23. Lu Y, Wang R, Zhang L, Li HL, Zheng QH, Zhou XD, et al. Apically extruded debris and irrigant with two NiTi systems and hand files when removing root fillings: a laboratory study. Int Endod J 2013;46:1125-30.

24. Brown DC, Moore BK, Brown CE Jr, Newton CW. An in vitro study of apical extrusion of sodium hypochlorite during endodontic canal preparation. J Endod 1995;21:587-91.

25. Topçuoğlu HS, Aktı A, Tuncay Ö, Dinçer AN, Düzgün S, Topçuoğlu G. Evaluation of debris extruded apically during the removal of root canal filling material using ProTaper, D-RaCe, and R-Endo rotary nickel-titanium retreatment instruments and hand files. J Endod 2014;40:2066-9.

26. Kustarci A, Altunbas D, Akpinar KE. Comparative study of apically extruded debris using one manual and two rotary instrumentation techniques for endodontic retreatment. J Dental Sci 2012;7:1-6.

27. Bürklein S, Schäfer E. Apically extruded debris with reciprocating single-file and full-sequence rotary instru- 
mentation systems. J Endod 2012;38:850-2.

28. Logani A, Shah N. Apically extruded debris with three contemporary $\mathrm{Ni}$-Ti instrumentation systems: an ex vivo comparative study. Indian J Dent Res 2008;19:182-5.
29. Kuştarci A, Akpinar KE, Er K. Apical extrusion of intracanal debris and irrigant following use of various instrumentation techniques. Oral Surg Oral Med Oral Pathol Oral Radiol Endod 2008;105:257-62. 